\title{
Expression of chemoresistance-related proteins in $\alpha$-fetoprotein-producing adenocarcinoma of the digestive organs
}

\author{
SHINGO KAMOSHIDA ${ }^{1}$, MAI SUZUKI ${ }^{1}$, YOICHI SAKURAI ${ }^{2}$, MASAHIRO OCHIAI $^{2}$, \\ FUMIKAZU KIMURA ${ }^{3}$, SADAHITO KUWAO ${ }^{3}$, KAZUKI SAKAMOTO ${ }^{4}$, \\ YOSHIKAZU SUGIMOTO ${ }^{4}$, MASAKAZU FUKUSHIMA ${ }^{4}$ and YUTAKA TSUTSUMI $^{1}$ \\ Departments of ${ }^{1}$ Pathology and ${ }^{2}$ Surgery, Fujita Health University School of Medicine, Toyoake, \\ Aichi; ${ }^{3}$ Division of Pathology, Higashi Yamato Hospital, Higashi-Yamato, Tokyo; \\ ${ }^{4}$ Taiho Pharmaceutical Co., Kawauchi, Tokushima, Japan
}

Received March 21, 2006; Accepted June 13, 2006

\begin{abstract}
. $\alpha$-fetoprotein-producing adenocarcinoma of the digestive organs (APAD) is known to show a poor prognosis. To clarify the characteristics of chemoresistance in APAD, three proteins of fluoropyrimidine chemotherapy association [dihydropyrimidine dehydrogenase (DPD), thymidine phosphorylase (TP) and thymidylate synthase (TS)] and one protein of cisplatin association [metallothionein (MT)] were immunohistochemically evaluated. Tissue samples were taken from 12 AFP-positive gastric cancers and 94 AFP-negative gastric cancers. Four AFP-positive cancer xenografts (one colonic, two pancreatic, and one biliary tract) and 17 AFP-negative cancer xenografts were also examined. In gastric cancers, high expression of TP was observed in 30\% of AFP-negative tumors but in none of AFP-positive tumors $(\mathrm{p}=0.03)$. High expression of MT was found in 30\% of AFP-negative tumors but in only one of the AFP-positive tumors. The TP-low and MT-low phenotype was noted in $92 \%$ of AFP-positive tumors and in $46 \%$ of AFP-negative tumors $(p=0.004)$. None of the AFPpositive cancer xenografts revealed high TP expression and only one showed high MT expression. In the cellular level, TP and MT were scarcely co-expressed with AFP in either gastric cancer or xenograft series, using double immunostaining and serial sectioning techniques. There were no significant differences in the expression of DPD and TS between AFP-positive group and -negative group. However, DPD was frequently co-expressed with AFP in poorly differentiated medullary areas of the AFP-positive gastric
\end{abstract}

Correspondence to: Dr Shingo Kamoshida, Department of Pathology, Fujita Health University School of Medicine, Toyoake, Aichi 470-1192, Japan

E-mail: skamo@fujita-hu.ac.jp

Key words: $\alpha$-fetoprotein, thymidine phosphorylase, metallothionein, fluoropyrimidine, cisplatin cancers. The data presented herein suggest that APAD should be sensitive to cisplatin, but resistant to capecitabine and 5'deoxyfluorouridine, fluoropyrimidines which are converted to 5-fluorouracil by TP. S-1, a fluoropyrimidine containing a strong DPD inhibitor, may be effective for AFP-positive gastric cancers with poorly differentiated medullary growth pattern.

\section{Introduction}

$\alpha$-fetoprotein (AFP) is an oncofetal protein produced by the fetal hepatocytes, yolk sac cells and some fetal gastrointestinal cells (1). AFP has been used clinically as a tumor marker of hepatocellular carcinomas (2) and germ cell tumors (3). In addition, elevated levels of serum AFP have been reported in patients with adenocarcinomas of the digestive organs (APAD), such as the stomach (4-14), colon (15), pancreas (16) and gallbladder (17). APAD has been associated with a poor prognosis because of frequent hematogenous metastasis to the liver (4-16). To develop effective therapy for APAD, a better understanding of the characteristics of APAD at the cellular and molecular levels is important.

Fluoropyrimidine-metabolizing enzymes are potentially important in regulating cellular sensitivity to fluoropyrimidines [5-fluorouracil (5-FU) and its prodrugs], which are the most widely used drugs for the treatment of solid cancers. The anticancer effects primarily depend on intratumoral levels of enzymes metabolizing the drugs (18). Dihydropyrimidine dehydrogenase (DPD) is a rate-limiting enzyme for degrading 5 -FU in the liver and other tissues, and a high level of DPD in tumor cells accelerates inactivation of 5-FU. Significant correlations between high expression levels of DPD and fluoropyrimidine resistance or poor prognosis have been described in several types of cancer (19-22).

Thymidylate synthase (TS) is the target enzyme of 5-FU, and the inhibition of TS activity is the principal mechanism of cytotoxicity. Several investigators have reported the clinical relevance of high TS expression as a predictor of the resistance to fluoropyrimidine-based chemotherapy (19,23-26). 
We recently demonstrated that high expression of TS was a predictor of the resistance to neoadjuvant chemotherapy with fluoropyrimidines (27), and was an important predictor of unfavorable recurrence-free interval and overall survival for colorectal cancer patients treated with fluoropyrimidine-based adjuvant chemotherapy (28).

Thymidine phosphorylase (TP) functions not only as an angiogenesis-inducing factor but also as a metabolic enzyme for 5-FU prodrugs, $\mathrm{N}^{4}$-pentyloxycarbonyl deoxyfluorocytidine (capecitabine) and 5'-deoxyfluorouridine (5'-DFUR) (18). Immunohistochemical studies have shown that gastric and breast cancers expressing high levels of TP respond to 5'DFUR-based regimens, resulting in a favorable survival of patients (29-31).

Metallothionein (MT) is a cysteine-rich protein with a high affinity for heavy metal ions such as zinc and cadmium, and overexpression of MT is associated with the resistance to cisplatin and radiation treatment $(32,33)$.

In the present study, to understand the characteristics of APAD from a viewpoint of chemotherapy, we analyzed the expression of a panel of chemoresistance-related proteins (fluoropyrimidine-related DPD, TS and TP, and cisplatinrelated MT) in gastric cancer tissues, and xenografts derived from adenocarcinomas of the digestive organs. Our results suggested that APAD should be sensitive to cisplatin but resistant to capecitabine and 5'-DFUR owing to low expression of MT and TP, respectively.

\section{Materials and methods}

Gastric cancer tissues. Between 2000 and 2004, in Fujita Health University Hospital, Toyoake, and Higashi-Yamato Hospital, Higashi-Yamato, 12 gastric cancers were diagnosed as AFP-positive. AFP was immunohistochemically detected in the resected specimens by the universal immuno-peroxidase polymer method, as described below. For comparison, 94 AFPnegative gastric cancers were also examined. All tissue samples were fixed in $10 \%$ formalin and embedded in paraffin.

Cancer xenografts. Seven gastric cancer cell lines (AZ-521, MKN-45, SC-2, SC-4, 4-1ST, ST-40 and TMK-1), five colonic cancer cell lines (COL-1, Co-3, HCT-15, KM12C and KM20C), six pancreatic cancer cell lines (AsPC-1, BxPC-3, MIAPaCa-2, PAN-3, PAN-4 and PAN-12), and three biliary tract cancer cell lines (BD-01, OCUG-1 and TGB14TKB) were used in the present study. AZ-521 and MKN-45 were purchased from JCRB (Osaka, Japan). HCT-15, AsPC-1, BxPC-3 and MIAPaCa-2 were obtained from ATCC (VA, USA). KM12C and KM20C were kindly provided by Dr K. Morikawa (Iwamizawa Worker's Compensation Hospital, Hokkaido, Japan). TMK-1 was kindly provided by National Cancer Center (Tokyo, Japan). OCUG-1 was purchased from Human Science Research Resources Bank (Osaka, Japan). TGBC14 $\mathrm{TKB}$ was obtained from Riken Bioresource Center (Ibaraki, Japan). Other cell lines were established at the Central Institute for Experimental Animals (Kawasaki, Japan). Cells were subcutaneously transplanted into nude mice. When the tumor volume reached $100 \mathrm{~mm}^{3}$, the mice were sacrificed, and tumors were fixed in $10 \%$ buffered formalin and embedded in paraffin wax. Animal experiments were carried out in accordance with the Guidelines for the Welfare of Animals in Experimental Neoplasia.

Immunohistochemistry. Serial sections, $3 \mu \mathrm{m}$-thick, were cut and mounted on aminopropyltriethoxysilane-coated glass slides. The sections were deparaffinized with xylene and rehydrated with graded alcohols. Endogenous peroxidase was inactivated by $0.03 \%$ hydrogen peroxide in methanol for 30 min. For the markers other than AFP and TP, heatinduced antigen retrieval was applied using a pressure cooker (Delicio 6L; T-FAL, Rumily, France) for $10 \mathrm{~min}$. Optimal soaking solutions were selected for the respective markers, determined by preliminary experiments: $10 \mathrm{mM}$ citrate buffer, $\mathrm{pH} 7.0$ for MT, and $1 \mathrm{mM}$ ethylenediaminetetraacetic acid solution, $\mathrm{pH} 8.0$ for DPD and TS. After pressure cooking, the sections were left at room temperature for cooling in the soaking solution for $30 \mathrm{~min}$. The sections were then incubated with the primary antibody, which reacts specifically with AFP (rabbit polyclonal, 1: 500 dilution, Dako, CA, USA), DPD (rabbit polyclonal, 1: 1000 dilution, Taiho Pharmaceutical, Tokushima, Japan), TP (mouse monoclonal, clone 2A4P4, 1: 1000 dilution, Taiho Pharmaceutical), TS (rabbit polyclonal, 1: 200 dilution, Taiho Pharmaceutical) or MT (mouse monoclonal, clone E9, 1: 1000 dilution; Dako), overnight at room temperature. Histofine ${ }^{\circledR}$ Simple Stain MAX-PO (Nichirei, Tokyo, Japan), employing the universal immunoperoxidase polymer method, was utilized as a second-layer reagent. The reaction products were visualized in $50 \mathrm{mg} / \mathrm{dl}$ 3,3'-diaminobenzidine tetrahydrochloride solution containing $0.003 \%$ hydrogen peroxide. Negative control studies were performed without applying the primary antibodies. As a positive control, sections known to be stained positively were included in each run.

Co-expression of AFP and chemoresistance-related proteins was evaluated for seven representative tumors (four gastric cancers, one colonic cancer xenograft and two pancreatic cancer xenografts) in which $>5 \%$ tumor cells were positive for AFP. The double immunostaining was performed, employing the universal immuno-alkaline phosphatase polymer method. The sections were incubated with anti-AFP polyclonal antibody overnight at room temperature. Histofine Simple Stain AP (Nichirei) was utilized as a second-layer reagent. Alkaline phosphatase activity was visualized in BCIP/NBT solution (one part of 5-bromo-4-chloro-3-indolyl phosphate solution, one part of nitroblue tetrazorium solution, and 200 parts of 0.1 M Tris buffer, $\mathrm{pH}$ 9.5). Dissociation of the antigenantibody complexes was then performed by hydrated heating, which also functions as antigen retrieval sequence, in the optimal soaking solutions for DPD, TS or MT immunostaining as previously described. The sections were incubated with antiDPD, TS, TP or MT antibody overnight at room temperature. After incubation with Histofine Simple Stain AP, the enzyme reaction was developed with Dako ${ }^{\circledR}$ Fuchsin+ SubstrateChromogen System (Dako).

Evaluation of the immunostained sections. The immunostained sections were independently assessed by two investigators (S.K. and M.S.). AFP expression was considered positive if any specific staining was detected. With regard to the chemoresistance-related proteins, the sections were classified 
Table I. Expression of chemoresistance-related proteins in AFP-positive and -negative gastric cancers.

\begin{tabular}{lccc}
\hline & $\begin{array}{c}\text { AFP-positive } \\
(\mathrm{n}=12)\end{array}$ & $\begin{array}{c}\text { AFP-negative } \\
(\mathrm{n}=94)\end{array}$ & $\mathrm{p}$-value \\
\hline DPD-high & $4(33 \%)$ & $23(24 \%)$ & \\
DPD-low & $8(67 \%)$ & $71(76 \%)$ & 0.50 \\
TS-high & $6(50 \%)$ & $53(56 \%)$ & \\
TS-low & $6(50 \%)$ & $41(44 \%)$ & 0.76 \\
TP-high & $0(0 \%)$ & $28(30 \%)$ & \\
TP-low & $12(100 \%)$ & $66(70 \%)$ & $0.03^{\mathrm{a}}$ \\
MT-high & $1(8 \%)$ & $28(30 \%)$ & \\
MT-low & $11(92 \%)$ & $66(70 \%)$ & 0.17 \\
TP-low and MT-low & $11(92 \%)$ & $43(46 \%)$ & \\
TP-high or MT-high & $1(8 \%)$ & $51(54 \%)$ & $0.004^{\mathrm{a}}$ \\
\hline
\end{tabular}

${ }^{a}$ Statistically significant.

into two groups based on the proportion of positively stained tumor cells in the lesion: a low group for tumors which were negative or positive but in $<30 \%$ of tumor cells, and a high group for tumors which were positive in $\geq 30 \%$ of tumor cells. The double-stained sections were classified into four groups as follows: -, co-expression of AFP and the chemoresistance-related protein is never observed; \pm , AFP-positive cells infrequently co-express the chemoresistance-related protein; +, AFP-positive cells occasionally co-express the chemoresistance-related protein; ++, AFP-positive cells frequently co-express the chemoresistance-related protein.

Statistical analysis. The Fisher's exact probability test was used for the assessment of differences between AFP-positive and AFP-negative groups. Statistical significance was set at $\mathrm{p}<0.05$

\section{Results}

Intracellular localization. AFP immunoreactivity was mainly observed as vesicular or granular structures in the cytoplasm, which correspond to rough endoplasmic reticula and Golgi apparati as its localization sites. DPD and MT were consistently localized in the cytoplasm of the cells. Positive staining for TS was observed in the cytoplasm but rarely in the nuclei. TP was expressed in both the cytoplasm and the nuclei.

Gastric cancer tissues. Of the 12 AFP-positive gastric cancers, 3 were poorly differentiated adenocarcinomas showing medullary growth partly with a papillary or tubular pattern. Two tumors consisted of high number of AFP-positive cells. The others were papillary or tubular adenocarcinomas, in which AFP-positive tumor cells were scattered.

The expression of DPD, TS, TP, and MT in AFP-positive and -negative gastric cancers is summarized in Table I. High expression of TP was found in $28(30 \%)$ of 94 AFP-negative
Table II. Expression of chemoresistance-related proteins in AFP-positive and -negative xenografts derived from adenocarcinoma of the digestive organs.

\begin{tabular}{lccr}
\hline & $\begin{array}{c}\text { AFP-positive } \\
(\mathrm{n}=4)\end{array}$ & $\begin{array}{c}\text { AFP-negative } \\
(\mathrm{n}=17)\end{array}$ & p-value \\
\hline Expression & $1(25 \%)$ & $5(29 \%)$ & \\
DPD-high & $3(75 \%)$ & $12(71 \%)$ & $>0.99$ \\
DPD-low & $3(75 \%)$ & $16(94 \%)$ & \\
TS-high & $1(25 \%)$ & $1(6 \%)$ & 0.35 \\
TS-low & $0(0 \%)$ & $6(35 \%)$ & \\
TP-high & $4(100 \%)$ & $11(65 \%)$ & 0.28 \\
TP-low & $1(25 \%)$ & $7(41 \%)$ & \\
MT-high & $3(75 \%)$ & $10(59 \%)$ & $>0.99$ \\
MT-low & $3(75 \%)$ & $5(29 \%)$ & \\
TP-low and MT-low & $12(71 \%)$ & 0.25 \\
TP-high or MT-high & $1(25 \%)$ & 12 & \\
\hline
\end{tabular}

tumors, while all the 12 AFP-positive tumors revealed low $\mathrm{TP}$ expression $(\mathrm{p}=0.03)$. High expression of MT was detected in $28(30 \%)$ of AFP-negative tumors but in only one $(8 \%)$ of AFP-positive tumors, the difference was not statistically significant $(\mathrm{p}=0.17)$. There was no significant relationship between AFP expression, and the positivity of DPD or TS. Low expression of both TP and MT was seen in 11 (92\%) of AFP-positive tumors and 43 (46\%) of AFP-negative tumors $(\mathrm{p}=0.004)$.

Cancer xenografts. Scattered AFP-positive tumor cells were found in one colonic cancer xenograft (Co-3), two pancreatic cancer xenografts (PAN-12 and AsPC-1), and one biliary tract cancer xenograft (OCUG-09). The colonic cancer xenograft was a well-differentiated adenocarcinoma, and the others were poorly differentiated adenocarcinomas. Table II shows the expression of DPD, TS, TP, and MT in cancer xenografts derived from adenocarcinomas of the digestive organs. High expression of TP was observed in six (35\%) of 17 AFPnegative xenografts, while all four AFP-positive xenografts revealed low TP expression ( $\mathrm{p}=0.28)$. High expression of MT was found in seven $(41 \%)$ of AFP-negative xenografts but in only one (25\%) of AFP-positive xenografts. The expression of DPD or TS did not show statistical difference between AFPpositive and -negative groups. The TP-low and MT-low phenotype was seen in three $(75 \%)$ of AFP-positive xenografts and five $(29 \%)$ of AFP-negative xenografts $(\mathrm{p}=0.25)$.

Co-expression of AFP and chemoresistance-related proteins. Table III shows co-expression of chemoresistance-related proteins in AFP-positive tumor cells in representative gastric cancer tissues and cancer xenografts. Double immunostaining or serial sections definitely demonstrated whether or not AFP and chemoresistance-related proteins are co-expressed in the same tumor cells. The co-expression of TS in AFP-positive tumor cells was identified in four of seven tumors. TP and MT were scarcely co-expressed with AFP. Co-expression of AFP 


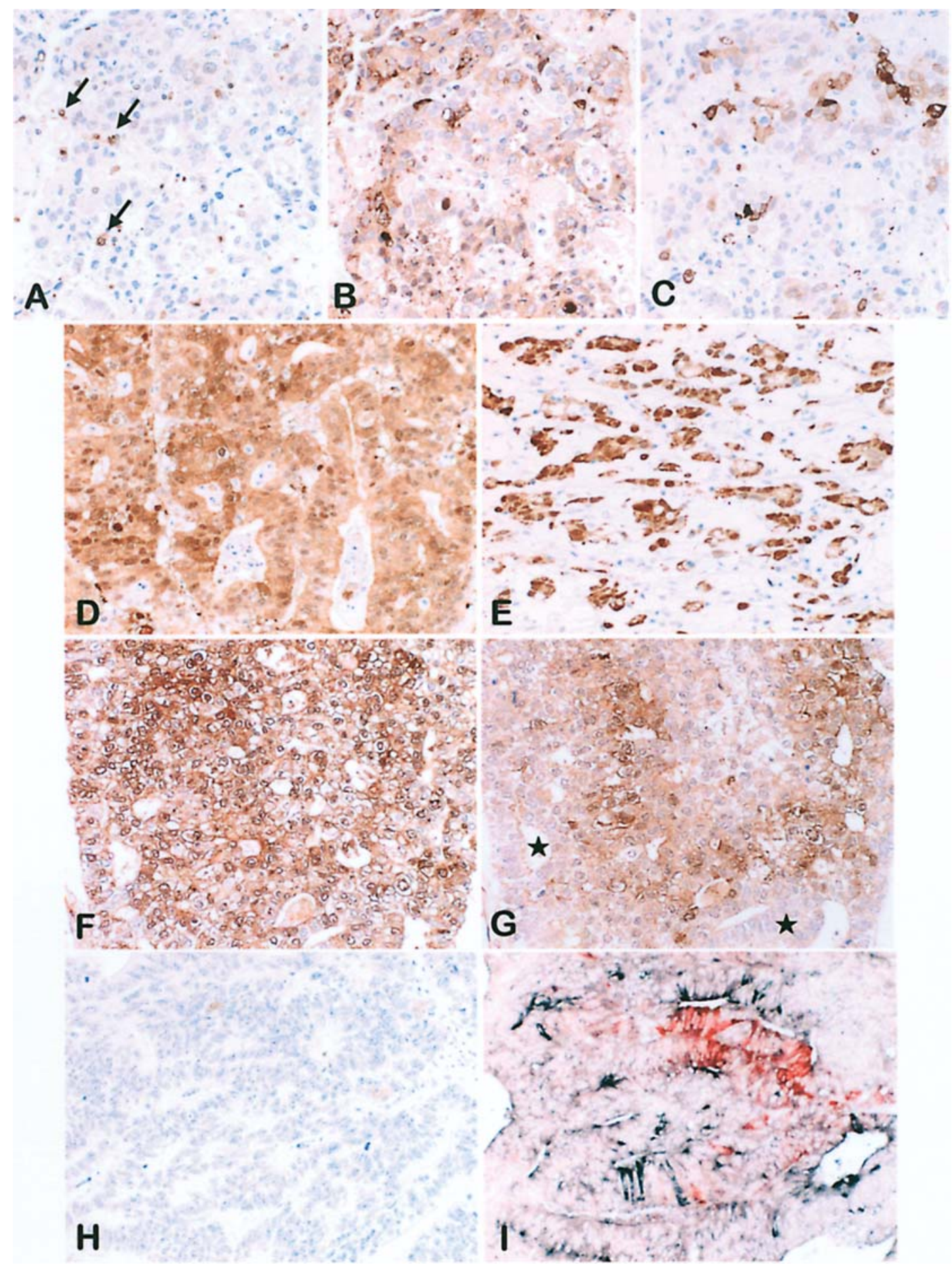

Figure 1. Expression of AFP and chemoresistance-related proteins. In AFP-positive gastric cancer, the tumor cells lacked immunoreactivity for TP (A), while macrophages in the stroma are positive for the enzyme (arrows). In serial sections, a good number of AFP-positive tumor cells (B) and a small number of MTpositive tumor cells (C) are noted, but no co-expression of AFP and MT is identified. In AFP-negative gastric cancer, a large number of tumor cells are immunoreactive for TP (D) or MT (E). In serial sections of AFP-positive gastric cancer showing a poorly differentiated medullary growth pattern, simultaneous expression of AFP (F) and DPD (G) is observed. However, the co-expression of AFP and DPD is not found in the tumor cells showing a tubular pattern (asterisks). In a colon cancer xenograft, no tumor cells are immunoreactive for TP (H). Double immunostaining (I) for AFP (black by BCIP/NBT) and MT (red by Fuchsin+) indicates that a number of tumor cells are immunoreactive for AFP and MT, but no co-expression of these proteins is observed. (Original magnification, x100)

and DPD was found in the gastric cancer cells with a poorly differentiated medullary pattern but not seen in the other areas of the gastric cancers, nor in the xenografts. Fig. 1 shows representative features of immunostaining for AFP and chemoresistance-related proteins in gastric cancers and a colon cancer xenograft.

\section{Discussion}

Patients with APAD have been reported to show a poor prognosis with a high incidence of liver metastasis (4-16). Thus, an individualized therapeutic regimen for APAD should be established. In the present study, in order to gain better 
Table III. Co-expression of chemoresistance-related protein in AFP-positive tumor cells in adenocarcinoma of the digestive organs.

\begin{tabular}{|c|c|c|c|c|c|}
\hline \multirow[b]{2}{*}{ Tumor } & \multirow[b]{2}{*}{ Histologic type } & \multicolumn{4}{|c|}{ Co-expression in AFP-positive tumor cells } \\
\hline & & DPD & $\mathrm{TS}$ & $\mathrm{TP}$ & MT \\
\hline \multirow[t]{2}{*}{ Gastric cancer 1} & por with med & + & - & + & \pm \\
\hline & $\bmod$ & \pm & - & - & \pm \\
\hline \multirow[t]{2}{*}{ Gastric cancer 2} & por with med & ++ & \pm & $-{ }^{\mathrm{a}}$ & $-{ }^{\mathrm{a}}$ \\
\hline & $\bmod$ & - & - & $-{ }^{\mathrm{a}}$ & $-\mathrm{a}$ \\
\hline \multirow[t]{2}{*}{ Gastric cancer 3} & por with med & $-{ }^{\mathrm{a}}$ & - & $-^{\mathrm{a}}$ & $-{ }^{\mathrm{a}}$ \\
\hline & pap & $-{ }^{\mathrm{a}}$ & - & $-{ }^{\mathrm{a}}$ & $-{ }^{\mathrm{a}}$ \\
\hline Gastric cancer 4 & $\bmod$ & - & - & $-\mathrm{a}$ & $-\mathrm{a}$ \\
\hline Colon cancer xenograft & wel & $-\mathrm{a}$ & + & $-^{\mathrm{a}}$ & \pm \\
\hline Pancreatic cancer xenograft 1 & por & $-{ }^{\mathrm{a}}$ & + & - & $-{ }^{\mathrm{a}}$ \\
\hline Pancreatic cancer xenograft 2 & por & $-\mathrm{a}$ & \pm & $-\mathrm{a}$ & - \\
\hline
\end{tabular}

${ }^{a}$ All tumor cells are negative for the chemoresistance-related protein. Por, poorly differentiated adenocarcinoma; med, medullary growth pattern; mod, moderately differentiated adenocarcinoma; wel, well differentiated adenocarcinoma; pap, papillary adenocarcinoma; AFPpositive tumor cells co-express the chemoresistance-related protein, frequently $(++)$, occasionally $(+)$, infrequently $( \pm)$, or never (-).

insight into the chemoresistance of APAD, we evaluated the immunohistochemical expression of DPD, TS, TP and MT in APAD in comparison with non-APAD. By applying double immunostaining or serial sections, it was possible to determine whether or not AFP expression correlated with the expression of chemoresistance-related proteins directly at the cellular level.

Capecitabine is converted to 5-FU through the intermediate metabolite 5'-DFUR. 5'-DFUR is metabolized to 5-FU by TP, also known as platelet-derived endothelial cell growth factor (17). Reportedly, expression levels of TP correlate with the tumor sensitivity to capecitabine and 5'-DFUR (29-31). In gastric cancers, high expression of TP was observed in $30 \%$ of AFP-negative tumors but in none of AFP-positive tumors $(\mathrm{p}=0.03)$. Similarly, Koide et al reported that in AFPproducing gastric cancers, TP was not expressed and thus was not involved in angiogenesis (11). These findings suggest that AFP-positive gastric cancers should be resistant to capecitabine and 5'-DFUR.

DPD is the rate-limiting enzyme in the catabolism of 5-FU (18). TS, a critical target for fluoropyrimidines, catalyzes the methylation of deoxyuridine monophosphate to deoxythymidine monophosphate, an essential step in DNA biosynthesis (18). Multiple clinical studies have suggested that overexpression of TS and DPD are closely associated with resistance to fluoropyrimidine-based chemotherapy (19-28). There were no significant differences in the expression of DPD or TS between AFP-positive gastric and -negative groups.

Histologically, AFP-producing gastric cancer tends to show the poorly differentiated medullary type, characterized by polygonal cells arranged in solid nests or sheets, or the well-differentiated papillary or tubular type with clear cytoplasm (5). DPD was co-expressed with AFP in the tumor cells in poorly differentiated medullary region of AFP-positive gastric cancers. The result suggests that AFP-positive gastric cancer cells growing with poorly differentiated medullary pattern should be resistant to 5-FU. Chang et al (34) reported that growth of two xenograft tumors, established from AFPproducing gastric cancers with poorly differentiated medullary pattern, was not suppressed by 5-FU. Nagai et al (8) described that the prognosis of AFP-positive gastric cancers with a poorly differentiated medullary pattern was particularly poor. $\mathrm{S}-1$ is a novel fluoropyrimidine consisting of tegafur, 5chloro-2, 4-dihydroxypyrimidine (CDHP, a strong DPD inhibitor) and potassium oxonate with a molar ratio of 1: 0.4: 1 (18), and shows an anti-tumor activity against tumors with high DPD activity (35).

MT is a cysteine-rich protein with a high affinity for heavy metal ions such as zinc and cadmium, and the overexpression of MT is associated with resistance to cisplatin and radiation treatment $(32,33)$. High expression of MT was found in $30 \%$ of AFP-negative gastric cancers but only one of the AFPpositive gastric cancers, the difference did not show statistical significance $(\mathrm{p}=0.17)$. Double immunostaining and serial sections directly demonstrated that most of AFP-positive gastric cancer cells, including medullary growth areas, were negative for MT. Chang et al (34) reported that AFP-producing gastric cancer cell line showed a marked regression of tumor growth after administration of cisplatin. AFP-producing gastric cancers, against which cisplatin-containing regimens were effective, have actually been reported by Japanese clinicians $(9,10,12,14)$.

In xenograft series, high expression of TP was observed in $35 \%$ of AFP-negative tumors, while all of AFP-positive tumors revealed low TP expression. High expression of MT was seen in $41 \%$ of AFP-negative xenografts but in only one of the AFP-positive xenografts. The lack of significant difference may reflect the relatively small number of xenografts studied. However, double immunostaining and serial sectioning methods confirmed that AFP-positive tumor cells were negative for TP or MT. Taken together, it is postulated that these AFP-positive adenocarcinoma cells likewise may show 
resistance to capecitabine and 5'-DFUR and the sensitivity to cisplatin. There was no significant relationship between AFP positivity, and the expression of DPD or TS.

In conclusion, the data presented herein suggest that APAD should be sensitive to cisplatin but resistant to capecitabine and 5'-DFUR owing to low expression of MT and TP, respectively. It is possible that $\mathrm{S}-1$ is effective in AFP-positive gastric cancers with a poorly differentiated medullary growth pattern. To our knowledge, this is the first study to perform simultaneous evaluation of immunohistochemical expression of DPD, TS, TP and MT in relation to AFP expression in adenocarcinomas of the digestive organs. Although the findings were based on the retrospective analysis of a limited number of tumors, we believe the data have relevant clinical implications. Prospective and retrospective clinicopathologic trials with a large sample size are required to confirm our results.

\section{Acknowledgements}

This work was in part supported by a Grant-in-Aid for Scientific Research (No. 17590321) from the Japan Society for Promotion of Science.

\section{References}

1. Gitlin D, Pericelli A and Gitlin GM: Synthesis of $\alpha$-fetoprotein by liver, yolk sac, and gastrointestinal tract of the human conceptus. Cancer Res 32: 979-982, 1972.

2. O'Conor GT, Tatarinov YS, Abelev GI and Uriel J: A collaborative study for the evaluation of a serologic test for primary liver cancer. Cancer 25: 1091-1098, 1970.

3. Motoyama T, Watanabe H, Yamamoto T and Sekiguchi M: Production of $\alpha$-fetoprotein by human germ cell tumors in vivo and in vitro. Acta Pathol Jpn 37: 1263-1277, 1987.

4. Chang YC, Nagasue N, Abe S, Taniura H, Kumar DD and Nakamura T: Comparison between the clinicopathologic features of AFP-positive and AFP-negative gastric cancers. Am J Gastroenterol 87: 321-325, 1992.

5. Kodama T, Kameya T, Hirota T, Shimosato Y, Ohkura H, Mukojima T and Kitaoka H: Production of $\alpha$-fetoprotein, normal serum protein, and human chorionic gonadotropin in stomach cancer: Histologic and immunohistochemical analysis of 35 cases. Cancer 48: 1647-1655, 1981.

6. Ishikura H, Kirimoto K, Shamoto M, Miyamoto Y, Yamagiwa H, Itoh T and Aizawa M: Hepatoid adenocarcinoma of the stomach: An analysis of seven cases. Cancer 58: 119-126, 1986.

7. Tsutsumi Y: Differentiation of gastric cancer cells: Analysis using immunohistochemistry and mucin histochemistry. In: Digestive Disease Pathology. Watanabe S, Wolff $M$ and Sommers SC (eds). Field \& Wood Inc., Philadelphia, pp1-49, 1988.

8. Nagai E, Ueyama T, Yao T and Tsuneyoshi M: Hepatoid adenocarcinoma of the stomach. A clinicopathologic and immunohistochemical analysis. Cancer 72: 1827-1835, 1993.

9. Gonda T, Ishida H, Higuchi T, Hirukawa H, Nakajima H, Hojo I and Mishima Y: A case of AFP ( $\alpha$-fetoprotein) producing gastric cancer successfully treated with EAP (etoposide, adriamycin, cisplatin) therapy (In Japanese with English abstract). Gan To Kagaku Ryoho 21: 1659-1663, 1994.

10. Hosokawa K, Kondo H and Yoshimori M: $\alpha$-fetoproteinproducing gastric cancer (In Japanese). Nippon Rinsyo 52 (Suppl 5): 234-237, 1994.

11. Koide N, Nishio A, Igarashi J, Kajikawa S, Adachi W and Amano J: $\alpha$-fetoprotein-producing gastric cancer: Histochemical analysis of cell proliferation, apoptosis, and angiogenesis. Am J Gastroenterol 94: 1658-1663, 1999.

12. Nagahama T, Maruyama M, Toukairin Y, Baba H, Yoshida T, Kure N, Ebuchi M, Yamada F and Ikeda T: Hepatic arterial injection therapy (HAI) for metastatic liver tumor from gastric cancer (In Japanese with English abstract). Gan To Kagaku Ryoho 27: 1920-1923, 2000.
13. Kono K, Amemiya H, Sekikawa T, Iizuka H, Takahashi A, Fujii $\mathrm{H}$ and Matsumoto Y: Clinicopathologic features of gastric cancers producing $\alpha$-fetoprotein. Dig Surg 19: 359-365, 2002.

14. Kochi M, Fujii M, Kaiga T, Takahashi T, Morishita Y, Kobayashi M, Kasakura Y and Takayama T: FLEP chemotherapy for $\alpha$-fetoprotein-producing gastric cancer. Oncology 66: 445-449, 2004.

15. Kurihara K, Konishi F, Kanazawa K, Fujii T and Saito K: $\alpha$-fetoprotein-producing carcinoma of the colon: Report of a case. Surg Today 27: 453-456, 1997.

16. Kawamoto S, Hiraoka T, Kanemitsu K, Kimura M, Miyauchi Y and Takeya $\mathrm{M}$ : $\alpha$-fetoprotein-producing pancreatic cancer - A case report and review of 28 cases. Hepatogastroenterology 39: 282-286, 1992.

17. Ikeda M, Okada S, Morozumi A, Fujino MA and Matsumoto Y: $\alpha$-fetoprotein producing carcinoma of the gallbladder associated with anomalous arrangement of the pancreaticobiliary ductal system - early detection through an attack of acute pancreatitis. Gastroenterol Jpn 27: 669-673, 1992.

18. Malet-Martino M and Martino R: Clinical studies of three oral prodrugs of 5-fluorouracil (capecitabine, UFT, S-1): A review. Oncologist 7: 288-323, 2002.

19. Huang CL, Yokomise H, Kobayashi S, Fukushima M, Hitomi S and Wada $\mathrm{H}$ : Intratumoral expression of thymidylate synthase and dihydropyrimidine dehydrogenase in non-small cell lung cancer patients treated with 5-FU-based chemotherapy. Int J Oncol 17: 47-54, 2000.

20. Horiguchi J, Takei H, Koibuchi Y, Iijima K, Ninomiya J, Uchida K, Ochiai R, Yoshida M, Yokoe T, Iino Y and Morishita Y: Prognostic significance of dihydropyrimidine dehydrogenase expression in breast cancer. Br J Cancer 86: 222-225, 2002.

21. Nakagawa T, Tanaka F, Takata T, Matsuoka K, Miyahara R, Otake Y, Yanagihara K, Fukushima M and Wada H: Predictive value of dihydropyrimidine dehydrogenase expression in tumor tissue, regarding the efficacy of postoperatively administered UFT (Tegafur + Uracil) in patients with p-stage I non-small cell lung cancer. J Surg Oncol 81: 87-92, 2002.

22. Hisamitsu K, Tsujitani S, Yamaguchi K, Fukuda K, Konishi I and Kaibara N: Expression of dihydropyrimidine dehydrogenase in cancer cells but not in stromal cells predicts the efficacy of fluorouracil treatment in patients with gastric carcinoma. Anticancer Res 24: 2495-2502, 2004.

23. Lenz H-J, Leichman CG, Danenberg KD, Danenberg PV, Groshen S, Cohen H, Laine L, Crookes P, Silberman H, Baranda J, Garcia Y, Li J and Leichman L: Thymidylate synthase mRNA level in adenocarcinoma of the stomach: A predictor for primary tumor response and overall survival. J Clin Oncol 14: 176-182, 1996.

24. Kuniyasu T, Nakamura T, Tabuchi Y and Kuroda Y: Immunohistochemical evaluation of thymidylate synthase in gastric carcinoma using a new polyclonal antibody: The clinical role of thymidylate synthase as a prognostic indicator and its therapeutic usefulness. Cancer 83: 1300-1306, 1998.

25. Yeh KH, Shun CT, Chen CL, Lin JT, Lee WJ, Lee PH, Chen YC and Cheng AL: High expression of thymidylate synthase is associated with the drug resistance of gastric carcinoma to high dose 5-fluorouracil-based systemic chemotherapy. Cancer 82 : 1626-1631, 1998.

26. Grau JJ, Domingo-Domenech J, Morente V, Pera M, Garcia-Valdecasas JC, Fuster J, Bombí A, Mellado B, Albanell $\mathrm{J}$ and Gascón P: Low thymidylate synthase expression in the primary tumor predicts favorable clinical outcome in resected gastric cancer patients treated with adjuvant tegafur. Oncology 66: 226-233, 2004.

27. Kamoshida S, Matsuoka H, Shiogama K, Matsuyama A, Shimomura R, Inada K, Maruta $M$ and Tsutsumi $Y$ : Immunohistochemical analysis of thymidylate synthase, p16 ${ }^{\text {INK4a }}$, cyclin-dependent kinase 4 and cyclin D1 in colorectal cancers receiving preoperative chemotherapy: Significance of p $16^{\text {INK } 4 a}$-mediated cellular arrest as an indicator of chemosensitivity to 5-fluorouracil. Pathol Intern 54: 564-575, 2004.

28. Kamoshida S, Matsuoka H, Shiogama K, Ishikawa T, Maeda K, Shimomura R, Inada K and Tsutsumi Y: Immunohistochemical evaluation of thymidylate synthase (TS) and $16^{\text {INK4a }}$ in advanced colorectal cancer: Implication of TS expression in 5-FU-based adjuvant chemotherapy. Jpn J Clin Oncol 34: 594-601, 2004. 
29. Yamamoto Y, Toi M and Tominaga T: Prediction of the effect of 5'-deoxy-5-fluorouridine by the status of angiogenic enzyme thymidine phosphorylase expression in recurrent breast cancer patients. Oncol Rep 3: 863-865, 1996.

30. Ishii R, Takiguchi N, Oda K, Koda K and Miyazaki M: Thymidine phosphorylase expression is useful in selecting adjuvant chemotherapy for stage III gastric cancer. Int J Oncol 19: 717-722, 2001.

31. Tominaga T, Toi M, Ohashi Y and Abe O: Prognostic and predictive value of thymidine phosphorylase activity in earlystage breast cancer patients. Clin Breast Cancer 3: 55-64, 2002.

32. Andrews PA, Murphy MP and Howell SB: Metallothioneinmediated cisplatin resistance in human ovarian carcinoma cells. Cancer Chemother Pharmacol 19: 149-154, 1987.
33. Xu H, Choi S-M, An C-S, Min Y-D, Kim K-C, Kim K-J and Choi C-H: Concentration-dependent collateral sensitivity of cisplatin-resistant gastric cancer cell sublines. Biochem Biophys Res Commun 328: 618-622, 2005.

34. Chang YC, Nagasue N, Kohno H, Ohiwa K, Yamanoi A and Nakamura T: Xenotransplantation of alpha-fetoprotein-producing gastric cancers into nude mice. Characteristics and responses to chemotherapy. Cancer 69: 872-877, 1992.

35. Fujiwara H, Terashima M, Irinoda T, Takagane A, Abe K, Nakaya T, Yonezawa H, Oyama K, Takahashi M, Saito K, Takechi T, Fukushima M and Shirasaka T: Superior antitumor activity of S-1 in tumours with a high dihydropyrimidine dehydrogenase activity. Eur J Cancer 39: 2387-2394, 2003. 